\title{
BMJ Global Health Decade of action on nutrition: our window to act on the double burden of malnutrition
}

\author{
Alessandro Rhyl Demaio, ${ }^{1,2}$ Francesco Branca ${ }^{1}$
}

To cite: Demaio AR, Branca F. Decade of action on nutrition: our window to act on the double burden of malnutrition. BMJ Glob Health 2017;3:e000492. doi:10.1136/ bmjgh-2017-000492

Handling editor Seye Abimbola

Received 25 July 2017 Revised 7 November 2017 Accepted 8 November 2017

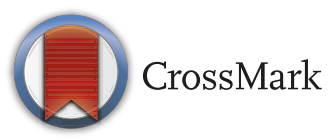

${ }^{1}$ Department of Nutrition for Health and Development, World Health Organization, Geneva, Switzerland

${ }^{2}$ Copenhagen School of Global Health, University of Copenhagen, Copenhagen, Denmark

Correspondence to Dr Alessandro Rhyl Demaio, Department of Nutrition for Health and Development, World Health Organization, Geneva, Switzerland; demaioa@who.int
The past half-century has seen a significant shift in the quality and quantity of human diets, and resulting epidemiology, worldwide. ${ }^{12}$ Nutrition and associated health and demographic transitions were once accepted as near-linear, gradual processes. Heavily influenced by rapid economic and income growth, globalisation, demographic changes and urbanisation, many nations are now experiencing a fast evolving and more complex nutrition reality.

In 2014 , approximately 1.9 billion adults were estimated to be overweight or obese ${ }^{3}$ while 462 million were underweight. ${ }^{4}$ An estimated 41 million children under the age of five were overweight or obese but 155 million were affected by stunting and 52 million by wasting by $2016^{5}$. In low-income and middle-income countries, almost 5 million children continued to die of undernutrition-related causes; yet, simultaneously many of these same populations now witness an unprecedented rise in childhood overweight and obesity.

The result is a double burden of malnutrition-the coexistence of undernutrition along with overweight and obesity or with nutrition-related noncommunicable disease. ${ }^{6}$ At the individual level, the double burden of malnutrition may manifest in two or more forms of simultaneous malnutrition-for example, obesity with nutritional anaemia or any vitamin or mineral deficiency or insufficiency. ${ }^{78}$ It can also occur across the life course and be temporally separated due to an evolving nutrition environment-for example, overweight in an adult who was previously stunted from childhood undernutrition or from intrauterine growth retardation. At the household level, a situation may arise with contrasting forms of malnutrition in multiple family members-for example, overweight in a mother with stunting in a child or nutritional anaemia in a mother with a grandparent who is overweight or type 2 diabetic.

\section{Summary box}

The double burden of malnutrition is the coexistence of undernutrition with overweight and obesity, or with nutrition-related noncommunicable disease, throughout the life course. This can occur at population, household andindividual levels.

- With optimal nutrition crucial to achieving the Sustainable Development Goals, the double burden of malnutrition offers an opportunity to consolidate efforts to tackle malnutrition and link established and successful initiatives with emerging nutrition interventions.

- The United Nations Decade of Action on Nutrition calls for coordinated action to address the double burden of malnutrition through cross-cutting and coherent policies and programmes.

- There are relatively untapped opportunities for collaborative strategies to encourage healthy diets through public, private and educational institutions, as well as in the home.

Finally, at the population level, when both undernutrition and overweight are prevalent in the same community, nation or region.

The major drivers of this double burden are varied and often insidious, including biological, environmental and behavioural determinants. It is increasingly understood, for example, that undernutrition early in life, and even in one's mother, may predispose to overweight later in life $^{9}$; that rapid weight gain in childhood can predispose to overweight and obesity in adulthood ${ }^{10}$; that influences known as the social determinants of health have a heavy impact on the nutrition opportunities and resulting status of individuals and populations ${ }^{11}$; and that the globalisation of unhealthy behaviours, driven by rapidly expanding international trade, has led to the commodification and homogenisation of diets-often higher in processed foods and saturated fats, salt and sugar, and lower in vitamins and minerals, than the traditional diets they replace. 
At the population level, this malnutrition phenomenon reflects a sequence of changes known as the nutrition transition, the demographic transition and the epidemiological transition. ${ }^{12}$ In the last two centuries, these three processes have occurred slowly and in a near-linear fashion in most high-income countries. The nutrition transition, along with the epidemiological and demographic transitions, resulted in intergenerational, incremental and controlled increases in population height, health and lifespan. The improved nutrition and higher caloric opportunity led to gradual increases in health. As low-income and particularly middle-income countries have continued to develop though, this process has been accelerated-with these transitions occurring over decades, rather than centuries. The result includes intragenerational changes in diet quality and quantity, leading to a coexistence or overlap of malnutrition types.

This double burden of malnutrition represents a major challenge to the international community, but it should also be seen as a profound opportunity for intervention. ${ }^{13}$ In the broader context of malnutrition in all its forms, this intersection of contrasting and often confounding forms of malnutrition lends a critical point for integrated action-an entry point for coordinated responses to infectious diseases, noncommunicable diseases, maternal and child illnesses and diseases associated with ageing. Addressing the double burden of malnutrition should also be seen as a catalyst for mitigating policy challenges beyond health, including economic inequality within populations, poverty and gender inequity. ${ }^{14}$

One must acknowledge the strong links between nutrition, educational achievement and economic development. Poor nutrition is associated with reduced cognitive function in individuals, delayed school enrolment, impaired concentration, increased illness and absenteeism and early school dropout-conferring up to a $20 \%$ lower earning capacity in adulthood. ${ }^{1516}$ Compared with non-stunted children, stunted children are $19 \%$ less likely to be able to read and $12 \%$ less likely to write simple sentences by the age of 8 , decreasing an individual's ability to take advantage of development resources and poverty alleviation opportunities. ${ }^{17}$ Inversely, the education of girls, in particular, contributes to gender equity, empowerment and improved maternal and child health outcomes, including improved offspring nutrition. Early life and childhood nutrition interventions may play a key role in achieving education for all and contributing to a dynamic, productive and skilful workforce.

The double burden of malnutrition is a largely unrecognised and underutilised opportunity for integrated action. As the global community transitions from a predominant focus on undernutrition within the framework of the Millennium Development Goals to the broader nutrition focus of the Sustainable Development Goals-including malnutrition in all its forms and noncommunicable diseases-the double burden of malnutrition offers a vital link between established and successful initiatives and emerging nutrition interventions. ${ }^{18}$ Possible concerns regarding such integrated nutrition approaches focused on the double burden include institutional, technical or funding-related dilution or inadvertently undoing or detracting from action and progress for undernutrition as we strive to address obesity and diet-related noncommunicable diseases. While further integrated research on the double-duty effects of specific interventions should be welcomed, it is important to note that individual studies suggest integrated approaches promise important efficiencies and double returns.

In this light, on 1 April 2016, the United Nations General Assembly adopted a United Nations Decade of Action on Nutrition for the period of 2016-2025. Framed by the Rome Declaration on Nutrition and the ICN2 Framework for Action, the Decade calls for coordinated action through cross-cutting and coherent policies, programmes and initiatives, including social protection to comprehensively address the double burden of malnutrition. ${ }^{14}$

One year on, the Decade outlined six action areas for policy as well as spotlighted the strong evidence that improved nutrition in the first 1000 days, from the start of pregnancy to 2 years of age, in pregnant and breastfeeding women and in adult women and adolescent girls, will have positive impacts on a range of public health challenges.

The Decade is an opportunity to highlight the shared importance of promoting and supporting adequate care and infant feeding practices, including early initiation of breastfeeding, exclusive breastfeeding during the first 6 months and continued breastfeeding until 2 years and beyond with appropriate complementary foods. It emphasises the relatively untapped opportunities for healthier diets through preschools, schools, public institutions, at workplaces and in the home-including the important role that families play in healthy eating.

The challenges posed by undernutrition, overweight and obesity and diet-related noncommunicable diseasesmay seem complex-but the solutions need not be. Through the identification, promotion and implementation of actions that synergistically address the double burden of malnutrition, we have a profound opportunity for intersectoral action in the dawning Decade, and in doing so, ending malnutrition in all its forms.

\section{Contributors $A D$ and FB drafted, edited and finalised the manuscript.}

Disclaimer The author(s) is(are) staff member(s) of the World Health Organization. The author(s) alone is(are) responsible for the views expressed in this publication and they do not necessarily represent the views, decisions or policies of the World Health Organization. ARD and FB are staff members of the WHO in Geneva. They alone are responsible for any views expressed in this publication and they do not necessarily represent the decisions or policies of any third party.

Competing interests None declared.

Provenance and peer review Commissioned; externally peer reviewed.

Open Access This is an open access article distributed under the terms of the Creative Commons Attribution-NonCommercial IGO License (CC BY-NC 3.0 IG0), which permits use, distribution,and reproduction for non-commercial purposes in any medium, provided the original work is properly cited. In any reproduction 
of this article there should not be any suggestion that WHO or this article endorse any specific organization or products. The use of the WHO logo is not permitted. This notice should be preserved along with the article's original URL. See: https:// creativecommons.org/licenses/by-nc/3.0/igo

○ World Health Organization [2017]. Licensee BMJ.

\section{REFERENCES}

1. Global status report on non communicable diseases. $2014 \mathrm{http} / / /$ apps.who.int/iris/bitstream/10665/148114/1/9789241564854_eng. pdf?ua $=1$

2. The state of food insecurity in the world. $2015 \mathrm{http} / / / \mathrm{www}$. fao.org/3/ a-i4646e/index.html

3. World Health Organization. Obesity and overweight: fact sheet. http://www.who.int/mediacentre/factsheets/fs311/en/

4. NCD Risk Factor Collaboration (NCD-RisC). Trends in adult bodymass index in 200 countries from 1975 to 2014: a pooled analysis of 1698 population-based measurement studies with $19 \cdot 2$ million participants. Lancet 2016;387:1377-96.

5. UNICEF/WHO/World Bank Group. Joint child malnutrition estimates: levels and trends in child malnutrition 2017 edition. 2017 http://www. who.int/nutgrowthdb/estimates2016/en/

6. World Health Organization. The double burden of malnutrition. In:Policy brief. Geneva: World Health Organization, 2017.

7. Thomas-Valdés S, Tostes M, Anunciação PC, et al. Association between vitamin deficiency and metabolic disorders related to obesity. Crit Rev Food Sci Nutr 2017:57:3332-43.

8. World Health Organization. Micronutrient deficiencies. http://www. who.int/nutrition/topics/vad/en/

9. Bruce KD, Hanson MA. The developmental origins, mechanisms, and implications of metabolic syndrome. J Nutr 2010;140:648-52.

10. Biro FM, Wien M. Childhood obesity and adult morbidities. Am J Clin Nutr 2010;91:1499S-505.

11. World Health Organization. Social determinants of health. http:// www.who.int/social determinants/en/

12. World Health Organization. Trade and investment: fact sheet. http:// www.who.int/trade/glossary/story050/en/

13. World Health Organization. Double-duty actions. In: Policy brief. Geneva: World Health Organization, 2017:55.

14. Rome Declaration on Nutrition. http://www.fao.org/3/a-ml542e.pdf

15. Jukes M. Early childhood health, nutrition and education. Background paper prepared for the education for all global monitoring report 2007: strong foundations: early childhood care and education. London: UNESCO, 2006.

16. Grantham-McGregor S, Cheung YB, Cueto S, et al. Developmental potential in the first 5 years for children in developing countries. Lancet 2007;369:60-70.

17. Save the Children. Food for thought: tackling child malnutrition to unlock potential and boost prosperity. $2013 \mathrm{http}: / / \mathrm{www}$. savethechildren.org/atf/cf/\%7B9def2ebe-10ae-432c-9bd0df91d2eba74a\%7D/FOOD_FOR_THOUGHT.PDF

18. Nutrition and the post-2015 sustainable development goals. http:// www.unscn.org/files/Publications/Nutrition The New_Post 2015 Sustainable_development_Goals.pdf 


\section{Correction: Decade of action on nutrition: our window to act on the double burden of malnutrition}

Demaio AR, Branca F. Decade of action on nutrition: our window to act on the double burden of malnutrition. BMJ Glob Health 2017;3:e000492. doi: 10.1136/ bmjgh-2017-000492.

This article was originally published in Volume 2, Issue 4 but has since been moved to Volume 3, Issue Supplement 1.

Open Access This is an open access article distributed under the terms of the Creative Commons AttributionNonCommercial IGO License (CC BY-NC 3.0 IGO), which permits use, distribution, and reproduction for non-commercial purposes in any medium, provided the original work is properly cited. In any reproduction of this article there should not be any suggestion that WHO or this article endorse any specific organization or products. The use of the WHO logo is not permitted. This notice should be preserved along with the articles original URL. See: https://creativecommons.org/licenses/ by-nc/3.0/igo

(C) World Health Organization [2018]. Licensee BMJ

BMJ Glob Health 2018;3:e000492corr1. doi:10.1136/bmjgh-2017-000492corr1 